\title{
Evidence for the Production of Ethylene by the Mycelium of Agaricus bisporus and its Relationship to Sporocarp Development
}

\author{
By T. WARD, ELIZABETH M. TURNER* \\ AND DAPHNE J. OSBORNE \\ Agricultural Research Council Unit of Developmental Botany, \\ I8I A Huntingdon Road, Cambridge CB3 oDY
}

(Received 3 August 1977)

The increased production of ethylene that occurs during the development of sporocarps of Agaricus bisporus results from increased formation by the compost but not by the casing layer. The increase depends on the presence of sporocarps up to a critical point in their development. It is concluded that the mycelium of $A$. bisporus in the compost is responsible for this ethylene production because no significant bacterial flora was found in the compost from fruiting cultures, and the mycelium growing on complex agar media also liberated ethylene. Mycelium growing on defined synthetic medium also evolved ethylene if methionine was supplied.

From the results of the different assays, there was no evidence for a regulatory role of ethylene in growth or development of $A$. bisporus.

\section{INTRODUCTION}

In a previous paper (Turner et al., 1975) the phasic production of sporocarps in Agaricus bisporus in crop beds and in culture flasks was shown to be associated with a phasic production of high levels of ethylene from the compost, the sporocarps themselves producing no detectable ethylene. It was proposed that the pattern of ethylene production was a metabolic marker of the expansion stages of the sporocarp.

From these experiments it was not possible to determine whether the ethylene was produced by the $A$. bisporus mycelium or by other micro-organisms present in the compost. Nor was it determined whether ethylene functioned as a growth regulator during the differentiation and development of the organism.

In this paper we report evidence to show that bacteria in the compost do not contribute to the ethylene production in vivo, and describe investigations of the relationship between sporocarp development and the appearance of the peaks of ethylene production. The production of ethylene by $A$. bisporus cultures in vitro and the regulatory role of ethylene during sporocarp development have also been studied.

\section{METHODS}

Organism. Agaricus bisporus (Lange) Sing. strains White Queen I02 and Sinden AI, both commercial white spawn strains, were used.

Commercial culture. Agaricus bisporus sporocarps and samples of compost and casing soil were obtained from the White Queen cropping unit and also from Messrs Knighton's Mushroom Farm, Somersham, Huntingdon. Mushrooms are grown commercially on a substrate of composted horse manure covered with

* Formerly of White Queen Ltd, Yaxley, Peterborough (now retired). 
a non-nutrient 'casing soil' on which sporocarps are produced when a suitable atmosphere is maintained. It has been shown (Eger, 1972) that for fruiting to occur it is necessary for bacteria to be present in the casing soil.

Culture on agar media. The following media, all containing $\mathrm{I} \cdot 5 \%(\mathrm{w} / \mathrm{v})$ agar, were used for culture of A. bisporus mycelium either in $9 \mathrm{~cm}$ diam. Petri dishes or in boiling tubes: (i) malt extract (Difco; $2.4 \%$, $\mathrm{w} / \mathrm{v})$; (ii) compost extract [boiling water/compost $(2: \mathrm{I}, \mathrm{v} / \mathrm{v})$ pressed through muslin]; (iii) defined minimal medium [modified from Treschow (I944)] containing $200 \mathrm{mg}$ each of $\mathrm{CaCO}_{3}, \mathrm{MgSO}_{4} \cdot 7 \mathrm{H}_{2} \mathrm{O}$ and $\mathrm{KCl}$, $2 \mathrm{mg} \mathrm{FeSO} \cdot 7 \mathrm{H}_{2} \mathrm{O}, 5 \mu \mathrm{g}$ vitamins (biotin and thiamin) and $\mathrm{I} \mathrm{g}$ ammonium tartrate in $\mathrm{I} 1$ distilled water, buffered at pH 6.8 with $\mathrm{KH}_{2} \mathrm{PO}_{4}$ and $\mathrm{Na}_{2} \mathrm{HPO}_{4}$ (0.0 I $\mathrm{M}$ final concentration). To this minimal medium carbon sources were added at a final concentration of $1 \%(\mathrm{w} / \mathrm{v})$; for medium supplemented with L-methionine at $7 \mathrm{~mm}$, the medium was prepared at double-strength and autoclaved, and an equal volume of double-strength L-methionine solution was then added aseptically through a Millipore filter $(0.22 \mathrm{~mm})$.

Culture in I 1 flasks. As previously described (Turner et al., 1975), I $50 \mathrm{~g}$ pasteurized compost was packed into I 1 conical flasks, and sterilized by autoclaving for $\mathrm{I}$ h at $126^{\circ} \mathrm{C}$ on two successive days. Flasks were then inoculated and incubated at $25^{\circ} \mathrm{C}$. A mixture of peat and chalk casing soil ( $150 \mathrm{~g}$ ) was then applied to the surface. To induce fruiting, the flasks were aerated using an inflow tube from above with a con-

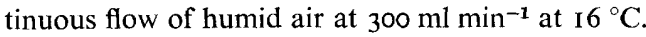

Determination of ethylene. Cultures on (i) compost in I I flasks, (ii) agar slopes in boiling tubes and (iii) samples of compost or casing soil $(6 \mathrm{~g})$ in boiling tubes, were sealed with Suba-seals for consecutive periods of 2 to $6 \mathrm{~h}$ to allow volatiles to accumulate. Gas samples ( $\mathrm{I} \mathrm{ml}$ ) were removed at intervals with a hypodermic syringe for analysis by gas-solid chromatography (for full details see Turner et al., 1975; Ward et al., 1977), and the mean linear rate of ethylene production was calculated relative to standards.

Culture in 'sacs'. Culture 'sacs' were set up in transparent plastic bags, $15 \mathrm{~cm}$ wide $\times 20 \mathrm{~cm}$ deep (kindly supplied by White Queen Ltd). Using a $10 \times 5 \mathrm{~cm}$ crystallizing dish as a mould, $50 \mathrm{~g}$ compost was packed into the sac, followed by another $100 \mathrm{~g}$ compost separated from the bottom layer by a sheet of muslin. The sac was closed with paper clips except for a central gap which was closed with a firm cotton wool plug (Fig. I). The sacs were then autoclaved for $\mathrm{I} h$ at $\mathrm{I} 26^{\circ} \mathrm{C}$, inoculated and incubated. Casing soil ( $100 \mathrm{~g}$ ) was then applied in an even layer over the surface. If non-sterile casing was used, the sac was opened and ventilated with humid air to induce fruiting; when sterile casing was used, the sac was kept closed and fruiting did not occur because of the absence of bacteria and the accumulation of $\mathrm{CO}_{2}$. Sterility of the casing was checked at the end of experiments by plating out samples on nutrient agar.

Isolation of bacteria from compost. Culture sacs were inverted in a laminar flow sterile cabinet (Airflow Developments, High Wycombe, Buckinghamshire) and the base of the bag was cut away using sterile scissors. The basal layer of compost was removed and discarded by lifting it out with the sheet of muslin. The central layer of the compost thus exposed was sampled; pieces of compost $(0.2$ to $0.5 \mathrm{~g})$ were removed using sterile forceps, and either streaked across an agar medium, or placed in McCartney bottles containing $10 \mathrm{ml}$ of liquid medium (media and incubation conditions are listed in Table 2). Bacterial development was scored as the number of colonies on agar, or visually as presence or absence in liquid media after 2 to 3 weeks incubation.

Ethylene treatment of mycelium on agar media. Plates of compost extract agar were inoculated centrally and incubated at room temperature in 61 glass containers. Atmospheres containing 10 , 100 and $1000 \mu 1$ ethylene $\mathrm{I}^{-1}$ were obtained by injecting the required quantity of the gas through Suba-seal closures. A $50 \mathrm{ml}$ beaker containing $20 \mathrm{ml}$ mercuric perchlorate $(0.25 \mathrm{M}$ in $2.5 \mathrm{M}$-perchloric acid) was included with the controls to absorb ethylene. Each container, with eight plates, was opened daily and colony diameter was measured at two marked positions. The containers were then closed and the ethylene atmosphere was renewed.

Ethylene treatment of cultures in I 1 flasks. Each flask was continuously aerated with an air stream at $300 \mathrm{ml} \mathrm{min}{ }^{-1}$. This contained filtered, humidified air for the controls, or $10 \mu 1$ ethylene $1^{-1}$, derived from a Mariotte bottle, for the treated cultures (Abeles, 1972). The timing of different stages of sporocarp development was recorded, and the weight and size of cap and stipe at the time of picking was determined.

Treatment of picked sporocarps with ethylene and $\mathrm{CO}_{2}$. Freshly harvested sporocarps of 35 to $40 \mathrm{~mm}$ cap diameter were halved longitudinally and the cap diameter and stipe length were measured at marked positions. The half sporocarps were placed in $10 \mathrm{ml}$ beakers standing on damp filter paper and enclosed in 61 glass containers. Ethylene and $\mathrm{CO}_{2}$ were injected via a Suba-seal to the desired concentration; controls contained $20 \mathrm{ml}$ mercuric perchlorate or $10 \mathrm{~g} \mathrm{KOH}$ in a $50 \mathrm{ml}$ beaker. The atmosphere was renewed after $24 \mathrm{~h}$. After $48 \mathrm{~h}$ the cap diameter, stipe length and spore drop were recorded. 


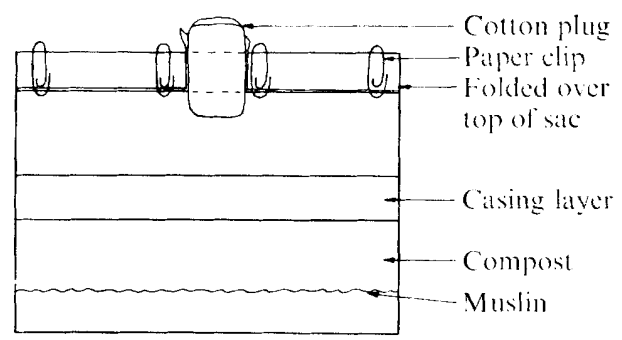

Fig. I. Diagrammatic representation of a culture sac.

\section{RESULTS}

Effect of removal of sporocarps on ethylene production in flask culture

Rates of ethylene production were measured daily in five replicate cultures in I 1 flasks during the fruiting period. Sporocarps were removed at the different stages of development shown to scale in Fig. 2.

The removal of a sporocarp nearing maturity [Fig. $2 e$, developmental stage 5 according to Hammond \& Nichols (1976)] resulted in a pattern of ethylene production which was essentially the same as that observed for unpicked sporocarps (Turner et al., 1975). If the sporocarps were picked at an earlier stage (Fig. $2 d$ ) then an attenuated peak of ethylene production occurred. When sporocarps were removed very early in their development (Fig. $2 a, b, c$ ) there was no increase in ethylene production. Microscopic examination of the gills during sporocarp development did not reveal a correlation between the production of ethylene and the development of spores.

\section{Comparison of ethylene production by compost and casing}

Rates of ethylene production by samples of colonized compost and casing are shown in Table I. Although fruiting was associated with a Io-fold rise in ethylene production by the compost, no parallel rise occurred in the casing. This indicates that the compost rather than the casing is the source of the increased ethylene production observed in whole cultures when sporocarps are produced.

\section{Isolation of bacteria from compost at fruiting}

The increased ethylene production in the compost could be due either to mycelium of A. bisporus or to casing bacteria which migrate into the sterilized compost. To clarify this, the level of bacterial contamination of the compost was investigated in sac cultures. Samples of compost were removed aseptically from sterile cultures and from fertile cultures at different stages of sporocarp development. Table 2 shows the growth of bacteria 2 to 3 weeks after transferring the compost samples into liquid media and on to agar plates.

In liquid media (Table $2 a$ ) there was bacterial growth from $15 \%$ of the samples from sterile cased compost, from $25 \%$ of the samples from compost bearing pins and from $22 \%$ of the samples from compost bearing cups. In controls manipulated in the same way, but not inoculated, $20 \%$ of the batches developed bacteria $; 2 \%$ of these controls also developed fungi.

On agar media three bacterial colonies developed from compost to which sterile casing had been applied. No colonies developed from compost bearing pins, two developed from compost bearing cups, and none were produced from compost from which fruit bodies had been picked 5 days previously.

We assume from these results that the number of bacteria present in the compost is very low, and that the mycelium of $A$. bisporus is therefore the source of the ethylene produced by the compost. 

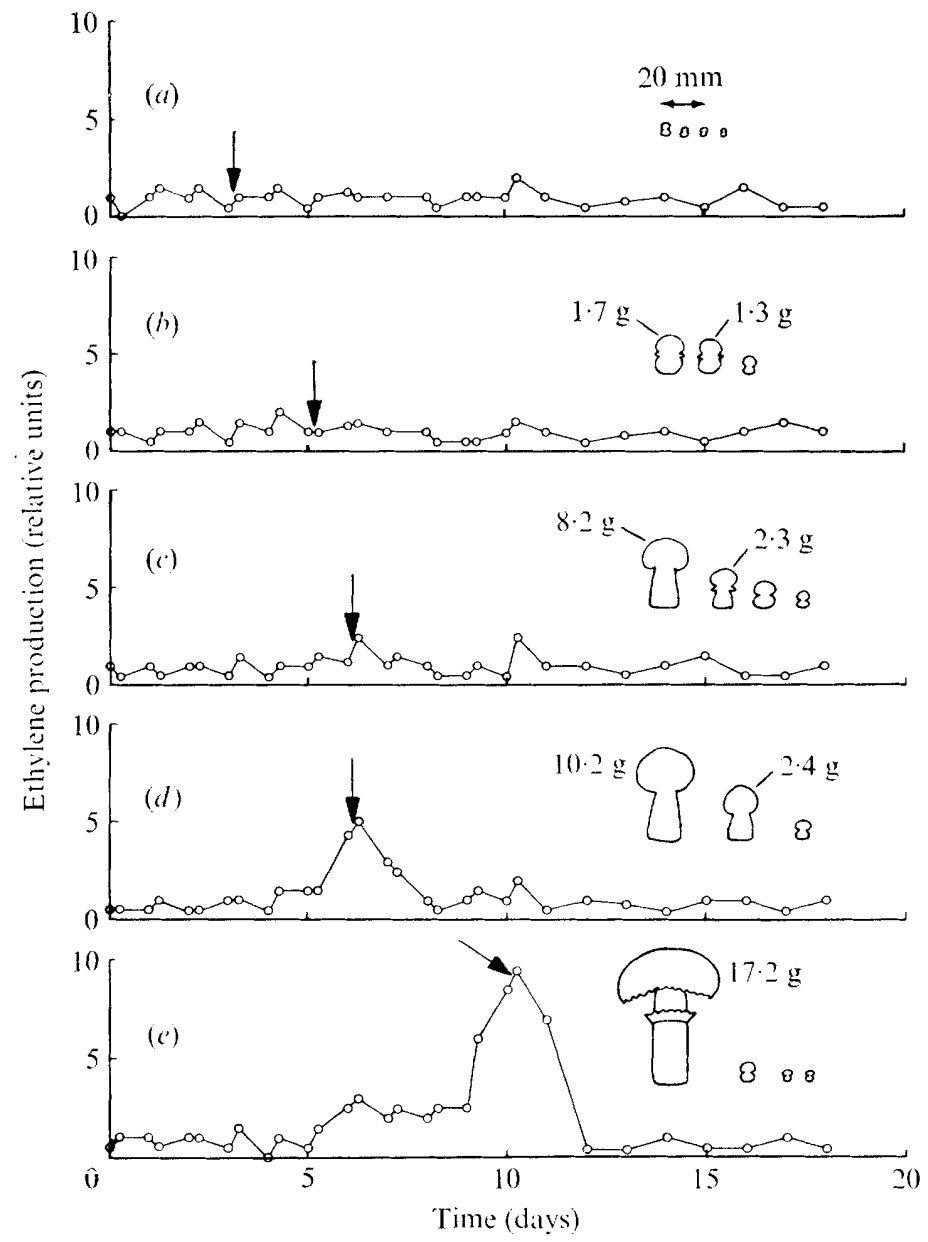

Fig. 2. Effect on ethylene production by fruiting cultures (strain White Queen 102) of removal of sporocarps at different stages of development. Arrows indicate when all the sporocarps were removed from the flask; insets represent their number, size and weight. Primordia developing later were also removed.

\section{Table I. Ethylene production from compost and casing}

Compost or casing $(6 \mathrm{~g})$ from fruiting or non-fruiting commercial cropping trays (strain White Queen I02) was enclosed in boiling tubes with Suba-seals and samples from the air space were taken at $2 \mathrm{~h}$ intervals for ethylene analysis.

Ethylene production (relative units per $2 \mathrm{~h}$ )

Compost

Fruiting

Non-fruiting

$30 \cdot 0 \pm 8 \cdot 5$

$3 \cdot 3 \pm 0 \cdot 8$

Casing

Fruiting

Non-fruiting
$2 \cdot 5 \pm 0 \cdot 3$

$2 \cdot 3 \pm 0 \cdot 8$ 
Table 2. Growth of bacteria from fruiting or sterile compost in culture sacs inoculated (a) into liquid media in McCartney bottles or $(b)$ on to $1.5 \%$ agar media in Petri dishes (strain Sinden AI)

Stages of sporocarp development in the sacs: A, non-fruiting; B, pins (inset, Fig. $2 b$ ); C, mature sporocarps (inset, Fig. 2e); D, 5 days after picking mature sporocarps (post Fig. $2 e$ ). Each sample was assayed in five replicate bottles or three replicate plates and the results for microbial growth are recorded for each: - , no microbial growth; + , bacterial growth (number of colonies on agar plates in parentheses).

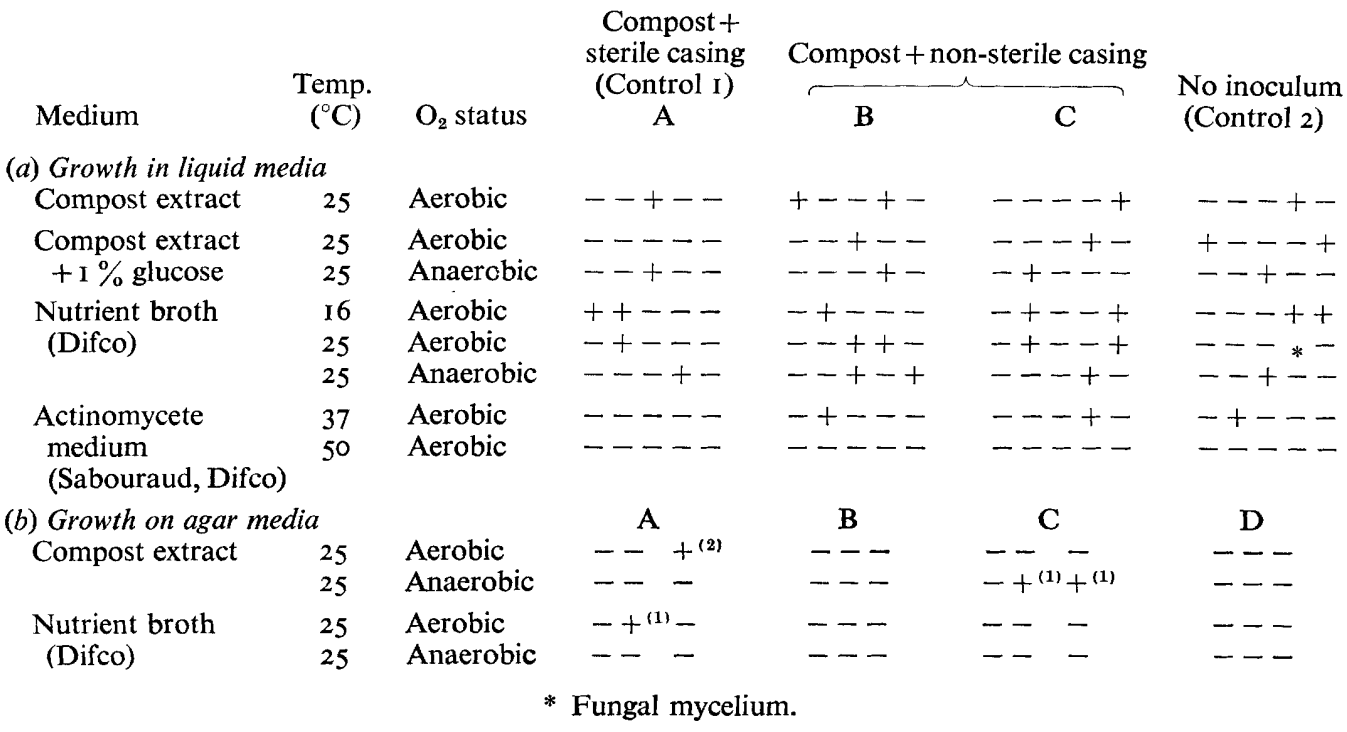

\section{Production of ethylene on agar media}

Ethylene was evolved from cultures of mycelium growing on agar media containing malt or extracts of compost. On minimal medium supplemented with a carbohydrate source, the amount of ethylene produced was no more than for the medium alone (Table $3 a$ ). The addition of methionine, however, led to high rates of ethylene production in the presence of the mycelium. The addition of a number of amino acids, other than methionine, did not result in increased ethylene production when mycelium was grown on minimal medium (Table $3 b$ ).

\section{Effect of ethylene on mycelial growth on agar media}

The high rates of ethylene formation by cultures containing methionine occurred despite the slow growth rate of the colonies. The growth rate of mycelium on compost extract agar is shown in Table 4. No significant differences were observed between cultures treated with 10 , 100 or $1000 \mu \mathrm{l}$ ethylene $1^{-1}$ and the controls in which ethylene was depleted, nor was there any visible difference in the morphology of the mycelium grown in these atmospheres.

\section{Effect of ethylene on the production of sporocarps by flask cultures}

The production of sporocarps by cultures (in I 1 flasks) treated with $10 \mu 1$ ethylene $1^{-1}$ or with normal air was recorded for a period of three consecutive breaks (fruiting periods). The following characteristics were measured: time from start of aeration to formation of sporocarp initials; time for development of initials into pins of to $\mathrm{mm}$ cap diameter; time for development of $10 \mathrm{~mm}$ pins into mature sporocarps; time between first and second breaks; weight of sporocarps per flask in each break and the cap to stipe ratio of the mature 
Table 3. Rates of ethylene production (per tube) from cultures of Sinden A I mycelium grown under different conditions

(a) Mycelium grown on agar media; ethylene production measured 24 days after inoculation

Composition of medium

Malt extract

Compost extract

Minimal medium $+1 \%$ soluble cellulose

Minimal medium $+1 \%$ insoluble cellulose

Minimal medium $+1 \%$ glucose

Minimal medium $+1 \%$ glucose +7 mm-methionine
Ethylene production* $\left(\mathrm{pl} \mathrm{h}{ }^{-1}\right)$

14
26
$<2$
$<2$
$<2$
64

* Values for uninoculated controls $(<4 \cdot 0)$ were subtracted from all results except for the medium containing methionine where the control value of $<9 \cdot 3$ was subtracted.

(b) Mycelium grown on minimal agar medium with $1 \%$ glucose and L-amino acid supplements (I $\mathrm{mM})$; ethylene production measured I4 days after inoculation

Supplement

None (control)

Methionine

Glutamic acid

Leucine

Cysteine

Alanine
Ethylene production $\left(\mathrm{pl} \mathrm{h}^{-1}\right)$

$4 \cdot 7 \pm 2 \cdot 9$
$* 23 \cdot 7 \pm 12 \cdot 0$
$9 \cdot 3 \pm 2 \cdot 9$
$3 \cdot 0 \pm 1 \cdot 7$
$5 \cdot 1 \pm 5 \cdot 0$
$2 \cdot 5 \pm 1 \cdot 7$

Colony area $\left(\mathrm{cm}^{2}\right)$

$$
\begin{aligned}
& 4.5 \pm 0 \\
& 0.7 \pm 0.4 \\
& 4.1 \pm 0.3 \\
& 2.6 \pm 0.3 \\
& 0.4 \pm 0 \\
& 1.6 \pm 0.3
\end{aligned}
$$

* Significant difference from control $(P<0.05)$.

Table 4. Growth of mycelium of A. bisporus on plates of compost extract agar maintained in ethylene-depleted air or in different concentrations of ethylene

Results are the average of eight replicates per treatment during the exponential phase of growth.

\begin{tabular}{|c|c|c|c|c|}
\hline \multirow[b]{3}{*}{$\mathrm{CO}_{2}$ conen } & \multicolumn{4}{|c|}{$\%$ Increase in size } \\
\hline & \multicolumn{2}{|c|}{ Air + MP } & \multicolumn{2}{|c|}{ Ethylene (100 $\mu \mathrm{l} \mathrm{l}^{-1}$ ) } \\
\hline & $\begin{array}{c}\text { Cap } \\
\text { diameter }\end{array}$ & $\begin{array}{l}\text { Stipe } \\
\text { length }\end{array}$ & $\begin{array}{c}\text { Cap } \\
\text { diameter }\end{array}$ & $\begin{array}{l}\text { Stipe } \\
\text { length }\end{array}$ \\
\hline $\begin{array}{l}\text { Without } \mathrm{CO}_{2} \\
(+\mathrm{KOH})\end{array}$ & $26 \cdot I \pm 2 \cdot 6$ & I $6 \cdot 9 \pm 4 \cdot 4$ & $26 \cdot 5 \pm 2 \cdot I$ & $18 \cdot 3 \pm 3 \cdot 5$ \\
\hline $\begin{array}{l}\text { Naturally } \\
\text { accumulated } \mathrm{CO}_{2}\end{array}$ & $16 \cdot 0 \pm 3 \cdot 8$ & $20 \cdot 1 \pm 3 \cdot 7$ & $16.0 \pm 3.5$ & $20 \cdot 4 \pm 6 \cdot I$ \\
\hline $\begin{array}{l}\text { Naturally accumulated } \\
\mathrm{CO}_{2}+2000 \mu 11^{-1}\end{array}$ & $14 \cdot 3 \pm I \cdot 5$ & $22 \cdot 5 \pm 4 \cdot 6$ & $I 5 \cdot 0 \pm I \cdot I$ & $24 \cdot 8 \pm 5 \cdot 6$ \\
\hline
\end{tabular}

$\begin{array}{ccccc} & \text { Air }+ \text { MP } & 10 & 100 & 1000 \\ \begin{array}{c}\text { Radial growth rate } \\ \left(\text { mm day }^{-1}\right)\end{array} & I \cdot 25 \pm 0.14 & I \cdot 19 \pm 0.13 & I \cdot 12 \pm 0.03 & I \cdot 30 \pm 0.15\end{array}$

MP, Mercuric perchlorate added to absorb ethylene (see Methods).

Table 5. Expansion of excised halved sporocarps (strain White Queen 102) treated with ethylene or ethylene-depleted air at different concentrations of $\mathrm{CO}_{2}$

Results are the average of eight replicates per treatment 
sporocarp. None of these comparisons showed a significant effect of ethylene, nor was there any observable effect on the gross morphology of the sporocarps.

\section{Effect of ethylene and $\mathrm{CO}_{2}$ on the expansion of picked sporocarps}

Turner (1977) has shown that picked sporocarps continue to expand under humid conditions, and that the expansion of the cap is reduced and the expansion of the stipe is increased by treatment with $\mathrm{CO}_{2}$. The expansion of halved sporocarps in the presence of $100 \mu$ l ethylene $1^{-1}$ or in ethylene-depleted air was determined at three concentrations of $\mathrm{CO}_{2}$ (Table 5). In agreement with the experiments of Turner (1977), $\mathrm{CO}_{2}$ inhibited the expansion of the cap; it also retarded maturation of the cap as expressed by the cap opening, gill depth and colour, and the release of spores. The presence of ethylene did not significantly affect any of these characteristics.

\section{DISCUSSION}

The increase in ethylene production from the compost during the maturation of sporocarps of $A$. bisporus described in our previous paper has now been shown to depend upon the continued presence of the sporocarp up to a certain critical stage of its development. If the sporocarps are picked at an early stage, ethylene production remains at a low level. If they are picked just before veil-break an attenuated peak of ethylene production occurs. However, the peak continues to develop to its maximum if sporocarps are picked after this stage. Clearly, the development of the sporocarps affects the ability of the remainder of the culture to produce ethylene. We have not determined the precise developmental stage involved, such as ripening and darkening of the gills, attainment of a certain mass, or onset of the phase of rapid expansion, but it would appear not to be directly related to spore formation.

The production of ethylene from the compost can now be attributed to the mycelium of $A$. bisporus and not to bacterial activity. Previously we showed that the increase in production at fruiting occurred mainly in the compost (Turner et al., 1975). The present experiments show that at the peak of ethylene production the casing layer (which contains the bacteria necessary to produce fruiting) does not contribute to the increase. Insignificant numbers of bacterial colonies were found during long term tests of previously sterilized compost covered with non-sterile casing, sampled from culture sacs that were fruiting well. Similar numbers of colonies developed from inocula from non-fruiting sacs with sterile casing or when the media had been manipulated but not inoculated; they were therefore assumed to be random contaminants. Although bacteria can produce ethylene (Freebairn \& Buddenhagen, 1964) and methionine can be a substrate (Primrose, 1976), there is no evidence for a large and active bacterial flora in the compost colonized by $A$. bisporus which could be responsible for the pattern of ethylene production.

The association of $A$. bisporus mycelium with ethylene production was further confirmed in the plate cultures. Low but significant amounts of ethylene were liberated on malt and compost extract media; on a defined synthetic medium significant amounts were formed only when methionine was included. It is suggested, therefore, that methionine could be a precursor for ethylene in $A$. bisporus. It is of interest that glutamic acid, a precursor in Penicillium digitatum (Chou \& Yang, I973), was not effective. The system of ethylene production from methionine in higher plants has, however, little similarity to that described for the fungus Mucor hiemalis (Lynch, 1972). Further investigations are necessary to determine which biosynthetic pathways occur in cased compost, and in pure cultures of A. bisporus.

We found no evidence of a regulatory role for ethylene during vegetative growth, fruiting or expansion of picked sporocarps, and unlike higher plants, no interactions were found between ethylene and $\mathrm{CO}_{2}$. Clearly, the high levels of ethylene that are produced during 
sporocarp enlargement, and which are not the product of the specific sporocarp-inducing bacteria, are related to this particular developmental stage of $A$. bisporus in a way that has yet to be determined.

One of us (T.W.) is indebted to Messrs Heinz for provision of a Research Grant for I year and to the ARC for support and research facilities. We thank Mr Peaker of White Queen and Mr Knighton of Knighton's Mushroom Farms for providing us with materials.

\section{REFERENCES}

ABELES, F. B. (1972). Biosynthesis and mechanism of action of ethylene. Annual Review of Plant Physiology 23, 259-292.

Chou, T. W. \& YANG, S. F. (1973). The biogenesis of ethylene in Penicillium digitatum. Archives of Biochemistry and Biophysics 157, 73-8I.

EGER, G. (1972). Experiments and comments on the action of bacteria on sporophore initiation in Agaricus bisporus. Mushroom Science 8, 719-725.

Freebairn, H. T. \& Buddenhagen, I. W. (1964). Ethylene production by Pseudomonas solanacearum. Nature, London 202, 3I 3-3I4.

Hammond, J. B. W. \& Nichols, R. (I976). Carbohydrate metabolism in Agaricus bisporus (Lange) Sing: changes in soluble carbohydrates during growth of mycelium and sporophore. Journal of General Microbiology 93, 309-320.

LYNCH, J. M. (1972). Identification of substrates and isolation of microorganisms responsible for ethylene production. Nature, London 240, 4546.
Primrose, S. B. (1976). Formation of ethylene by Escherichia coli. Journal of General Microbiology 95, I 59-I 65.

TrESCHOW, C. (1944). Nutrition of the cultivated mushroom. Dansk botanisk Arkiv II, I-I 80.

Turner, E. M., Wright, M., Ward, T., Osborne, D. J. \& SelF, R. (1975). Production of ethylene and other volatiles and changes in cellulase and laccase activities during the life cycle of the cultivated mushroom, Agaricus bisporus. Journal of General Microbiology 91, I67-176.

TuRnER, E. M. (1977). Development of excised sporocarps of Agaricus bisporus and its control by $\mathrm{CO}_{2}$. Transactions of the British Mycological Society 69 (in the Press).

Ward, T. M., Wright, M., Roberts, J. A., Self, R. \& OsBorne, D. J. (I977). Analytical procedures for the assay and identification of ethylene. In Isolation of Plant Growth Substances. Edited by J. R. Hillman. Cambridge: Cambridge University Press. (In the Press.) 